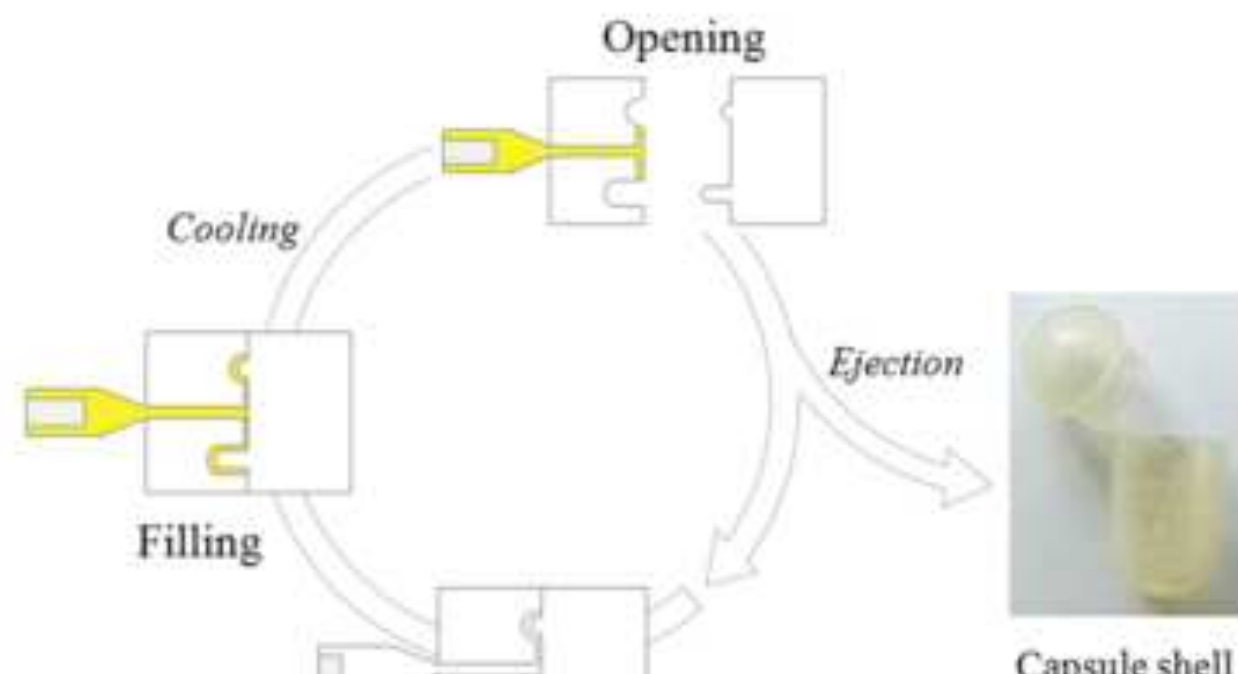

Capsule shell
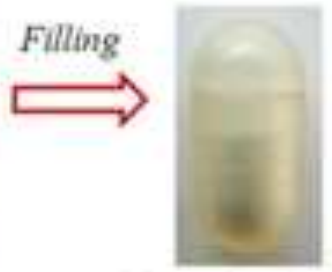

Capsular device

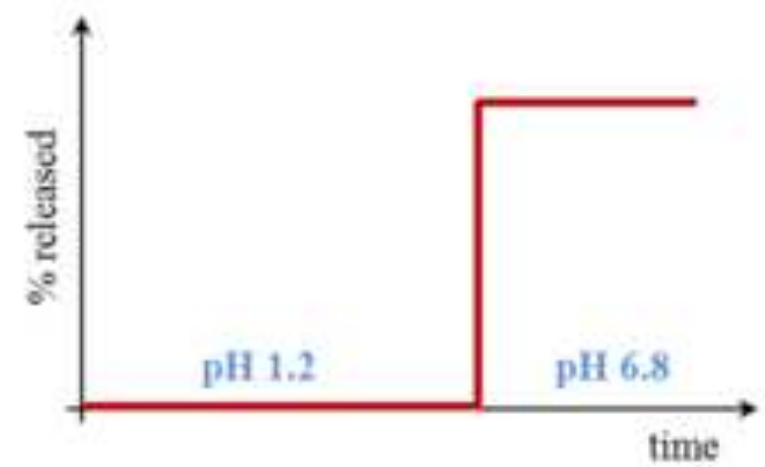

Closing 


\section{GASTRORESISTANT CAPSULAR DEVICE PREPARED BY INJECTION MOLDING}

Lucia Zema, Giulia Loreti, Alice Melocchi, Alessandra Maroni, Luca Palugan, Andrea Gazzaniga*

Dipartimento di Scienze Farmaceutiche, Università degli Studi di Milano, via G. Colombo 7120133 Milano, Italy

5

*Corresponding author (A. Gazzaniga) phone: +39 2 50324654; fax: +39 250324658

e-mail address: andrea.gazzaniga@unimi.it 
In the present work, the possibility of manufacturing by Injection Molding (IM) a gastro-resistant capsular device based on hydroxypropyl methyl cellulose acetate succinate (HPMCAS) was investigated. By performing as an enteric soluble container, such a device may provide a basis for the development of advantageous alternatives to coated dosage forms. Preliminarily, the processability of the selected thermoplastic polymer was evaluated, and the need for a plasticizer (polyethylene glycol 1500) in order to counterbalance the glassy nature of the molded items was assessed. However, some critical issues related to the physical/mechanical stability (shrinkage and warpage) and opening time of the device after the $\mathrm{pH}$ change were highlighted. Accordingly, an in-depth formulation study was carried out taking into account differing release modifiers potentially useful for enhancing the dissolution/disintegration rate of the capsular device at intestinal $\mathrm{pH}$ values. Capsule prototypes with thickness of 600 and $900 \mu \mathrm{m}$ containing Kollicoat ${ }^{\circledR}$ IR and/or Explotab ${ }^{\circledR}$ CLV could be manufactured, and a promising performance was achieved with appropriate gastric resistance in $\mathrm{pH} 1.2$ medium and break-up in $\mathrm{pH} 6.8$ within $1 \mathrm{~h}$. These results would support the design of a dedicated mold for the development of a scalable manufacturing process.

\section{Keywords:}

injection molding (IM); micromolding; capsular device; gastric resistance; enteric polymer; hydroxypropyl methyl cellulose acetate succinate (HPMCAS) 


\section{Introduction}

Preventing the chemical degradation of active principles in the acidic environment of the stomach and protecting the gastric mucosa from irritation phenomena induced by drug assumption are the two main reasons for conceiving gastro-resistant dosage forms (Dulin, 2010). Such formulations are also used to pursue selective release into particular regions of the intestinal tract, either to exploit favorable absorption sites or provide treatment for local diseases. Moreover, according to a time-dependent strategy, the colon can be targeted by enteric-coated pulsatile delivery systems able to provide lag phases starting on gastric emptying, with the coating dissolution, and lasting throughout the small intestinal transit time (SITT) (Davis, 1985; Gazzaniga et al., 1994; Gazzaniga et al., 2006).

Gastric resistance is generally obtained by means of polymers with $\mathrm{pH}$-dependent solubility; the most widely employed are acrylic and metacrylic acid copolymers (e.g. Eudragit L, S and FS), polyvinyl acetate phthalate (PVAP) and cellulose derivatives (e.g. cellulose acetate phthalate, CAP; hydroxypropyl methyl cellulose acetate succinate, HPMCAS) (McGinity and Felton, 2008). These are applied onto drug-containing solid cores (tablets, capsules, pellets, granules) using different techniques that can basically be distinguished according to the amount of solvent required, preferably water, and the role it would play in the coating process. Large amounts of liquid to be dried are in fact involved in the deposition of gastro-resistant layers from polymeric solutions or suspensions (film-coating technique) (Bianchini et al., 1991; Felton et al., 1995; Nastuzzi et al., 2000; Siepmann et al., 2006). On the other hand, in order to avoid the use of water thus overcoming stability issues and drawbacks associated with the need for solvent removal, dry-coating techniques were proposed, such as conventional compaction-based processes (press-coating technique) (Cerea et al., 2008a; Blubaugh et al., 1958; Fukui et al., 2001a; Fukui et al., 2001b). More sophisticated approaches envisage the deposition onto core substrates of liquid (non-aqueous) or solid (powder blends) coating agents, and subsequent formation of a continuous layer by solidification/polymerization or heatcuring (Lau and Gleason, 2007; Obara et al., 1999; Kablitz et al., 2006; Cerea et al., 2008b). Despite the improvements in terms of process time, manufacturing costs and stability of the final product, the industrial scale-up and availability of suitable coat-forming agents still represent major limitations to a wider diffusion of dry-coating techniques.

In the case of enteric-coated products intended to release the active ingredient as soon as they are emptied from the stomach, a rapid disintegration/dissolution of the coating layer is expected. This is especially important when drugs having an absorption window in the upper part of the small intestine are dealt with (Liu and Basit, 2010). It was recently highlighted that gastro-resistant systems can take up to 2 hours for a complete exposure of the core to the intestinal fluids, thus potentially affecting the drug bioavailability and the efficacy of the therapy (McConnell et al., 2008).

65 In coating processes an important role is generally played by the drug-containing core, the physical (shape, dimension, surface), technological (thermal resistance, hardness, friability, wettability, disintegration/dissolution tendency) and stability characteristics of which may constrain or even impair each 
of the above-mentioned techniques (Felton and McGinity, 1996; Cole et al., 2002; Felton and McGinity, 2003; Porter and Felton, 2010).

Based on the above-discussed premises, the possibility of preparing container-like enteric-soluble devices that could be filled and sealed after manufacturing would represent an innovative and advantageous alternative to the design of coated gastro-resistant dosage forms. In this respect, hollow HPMCAS or PVAP pipes were prepared by hot-melt extrusion, manually filled with a model drug powder and heat-sealed at their open ends, thus providing enteric devices that showed promising results (Mehuys et al., 2005). Injection molding (IM), which involves the injection of appropriately softened/melted materials into a mold wherein they are given a definite three-dimensional shape, was proven a viable technique in the preparation of capsular items composed of separately-manufactured parts to be matched after filling with various formulations (powders, granules/pellets, semi-solids or liquids) through well-established processes (Zema et al., 2012). The performance of such devices would depend on their composition and design features (morphology and thickness of the shell) only, in spite of differing characteristics of the conveyed drug and/or formulation, which could offer major benefits in terms of time and costs required for development. Moreover, they would be ready-to-use, i.e. easy to be filled for extemporaneous preparations. Molded capsular shells composed of potato starch $\left(\mathrm{Capill}^{\circledR}\right)$ were proposed to replace commercial gelatin or HPMC capsules intended for immediate release (IR) (Eith et al., 1986; Vilivalam et al., 2000). More recently, IM was successfully employed to prepare a capsular pulsatile delivery device based on swellable/erodible polymers (hydroxypropyl cellulose, HPC) (Gazzaniga et al., 2011a; Gazzaniga et al., 2011b; Gazzaniga et al., 2011c).

In the present work, the feasibility of IM in the preparation of HPMCAS-based capsules was explored with the aim of developing a gastro-resistant shell to be used as an innovative delivery platform for enteric dosage forms.

\section{Materials and Methods}

\subsection{Materials}

Hydroxypropyl methyl cellulose acetate succinate (HPMCAS, AQUOT-LG ${ }^{\circledR}$; Shin-Etsu, Japan), polyethylene glycol (PEG 1500; Clariant Masterbatches, Italy), sodium starch glycolate (Explotab ${ }^{\circledR}$ CLV; JRS, Germany) ( $\left.\mathrm{d}_{10}=10 \mu \mathrm{m} ; \mathrm{d}_{50}=25 \mu \mathrm{m} ; \mathrm{d}_{90}=52 \mu \mathrm{m}\right)$, polyvinyl alcohol-polyethylene glycol graft copolymer (Kollicoat ${ }^{\circledR}$ IR; BASF, Germany) $\left(d_{10}=9 \mu \mathrm{m} ; d_{50}=23 \mu \mathrm{m} ; d_{90}=55 \mu \mathrm{m}\right.$ ), dipotassium hydrogen phosphate anhydrous $\left(\mathrm{K}_{2} \mathrm{HPO}_{4}\right.$; Carlo Erba, Italy $)\left(\mathrm{d}_{10}=2 \mu \mathrm{m} ; \mathrm{d}_{50}=6 \mu \mathrm{m} ; \mathrm{d}_{90}=24 \mu \mathrm{m}\right)$, sodium hydrogen carbonate $\left(\mathrm{NaHCO}_{3}\right.$; Carlo Erba, Italy) $\left(\mathrm{d}_{10}=15 \mu \mathrm{m} ; \mathrm{d}_{50}=28 \mu \mathrm{m} ; \mathrm{d}_{90}=63 \mu \mathrm{m}\right)$, acetaminophen (Atabay, Turkey) $\left(\mathrm{d}_{10}=14 \mu \mathrm{m} ; \mathrm{d}_{50}=29 \mu \mathrm{m} ; \mathrm{d}_{90}=58 \mu \mathrm{m}\right)$. 


\subsection{Methods}

\subsubsection{IM process}

IM was performed by a bench-top micromolding machine (BabyPlast 6/10P, Cronoplast S.L.; Rambaldi S.r.l., Italy).

The polymeric formulations were prepared by co-grinding HPMCAS and PEG 1500 in a blade mill; blends containing release modifiers were obtained by mixing in turbula (Type T2C, WAB, Switzerland) for 20 min. Prior to use, all materials except for PEG 1500 were kept in a ventilated oven at $40{ }^{\circ} \mathrm{C}$ for $24 \mathrm{~h}$. In Table 1 the composition ( $\%$ by weight) of the molded polymeric formulations is reported.

Before processing, the behavior of the polymer and polymeric formulations when subjected to heating or IM was evaluated as follows.

Hot-plate experiment. 2-3 g of polymer/polymeric formulation were placed in an aluminum pan on a hot plate and heated under continuous manual mixing, while gradually increasing the temperature up to $200{ }^{\circ} \mathrm{C}$. Samples were checked for overall aspect, color, texture and mechanical characteristics during heating and after cooling.

Air shot test. $50 \mathrm{~g}$ of polymer/polymeric formulation were loaded into the IM press through the hopper and expelled from the injecting unit as during a purge operation (Rosato et al., 2000). The test was repeated under different operating temperatures. Samples were checked for overall aspect, color and mechanical characteristics immediately after ejection and when solidified.

\subsubsection{Manufacturing of molded items}

$50 \mathrm{~g}$ of polymeric formulation were loaded into the plasticating chamber of the IM press through the hopper and then conveyed by means of a first piston to the injecting chamber. By successively applying two distinct pressures, each for a defined period of time and at a selected rate, another piston (10 $\mathrm{mm}$ diameter) injected a specific amount of melt (charge) through a $1 \mathrm{~mm}$ diameter nozzle into the mold cavity (disk or capsular shape). Prior to product ejection, the mold was kept closed by applying a closing pressure to allow the injected melt to cool down and harden. The rate of each process stage was expressed as $\%$ of the maximum value.

Molded items were prepared by means of two different molds: $i$ ) a $30 \mathrm{~mm}$ diameter disk-shaped mold 130 provided with a central gate, enabling the selection of differing thicknesses $(200,400$, and $600 \mu \mathrm{m})$ and $i i)$ a capsular mold with two cavities for the cap ( $8 \mathrm{~mm}$ height and $8 \mathrm{~mm}$ diameter) and the body (11 $\mathrm{mm}$ height and $8 \mathrm{~mm}$ diameter), respectively, each provided with a lateral gate, enabling the preparation of matching items within a single manufacturing cycle and the selection of differing shell thicknesses (300, 600, and 900 $\mu \mathrm{m})$ (Gazzaniga et al., 2011b). The operating conditions were varied within different ranges of values according to whether disks or capsules were employed (Table 2). Molds were manually lubricated with peanut oil approximately every 15-20 units manufactured. The first unit obtained after this operation was discarded. 


\subsubsection{Characterization of molded items}

Molded items, i.e. disks and assembled capsule shells, were checked for weight (analytical balance BP211, Sartorius, Germany; $\mathrm{n}=10$ ) and thickness (digimatic indicator ID-C112X, Mitutoyo, Japan; $\mathrm{n}=10$ ). Digital photographs (Nikon D70, Nikon, Japan) of molded items were acquired, and photomicrographs were taken by scanning electron microscope (SEM; Sigma, Zeiss, Germany) after gold sputtering $(10 \mathrm{~nm})$. The characterization was performed immediately after ejection, except for photomicrographs, and after 24 hours storage at ambient conditions $\left(24 \pm 2^{\circ} \mathrm{C} / 55 \pm 5 \% \mathrm{RH}\right)$. Photomicrographs of a few molded disks were also collected after incubation in unstirred $\mathrm{pH} 6.8$ phosphate buffer at room temperature for $120 \mathrm{~min}$ and drying in a ventilated oven at $40{ }^{\circ} \mathrm{C}$ for $24 \mathrm{~h}$.

\subsubsection{Evaluation of gastric resistance performance}

Disks. Immediately after ejection disks were positioned on manually-assembled cells modified from the extraction cells used in the dissolution test for transdermal patches (Ph. Eur. 7) (Figure 1). The reservoir compartment was loaded with an amount of a powder tracer (acetaminophen) ranging from 43 to $48 \mathrm{mg}$. The surface exposed to the acceptor fluid was $177 \mathrm{~mm}^{2}$. The test $(\mathrm{n}=3)$ was performed in pharmacopoeial

155 apparatus 2 (Dissolution System 2100B, Distek, New Jersey) at $100 \mathrm{rpm}$ under the conditions of the Dissolution test for delayed-release dosage forms (Method B, USP 34) except for the medium volume (600 $\mathrm{mL}$ ). Fluid samples were withdrawn at fixed time points and assayed spectrophotometrically at $254 \mathrm{~nm}$ (spectrophotometer lambda25, Perkin Elmer, Massachusetts).

Capsular devices. Each capsule body was manually filled with an amount of a powder tracer (acetaminophen) ranging from 86 to $92 \mathrm{mg}$ and closed with a matching cap. The gastric resistance performance $(n=3)$ was evaluated in pharmacopoeial apparatus 2 (Dissolution System 2100B, Distek, New Jersey) at $100 \mathrm{rpm}$ under the conditions of the Dissolution test for delayed-release dosage forms (Method B, USP 34). Fluid samples were withdrawn and assayed as above reported. Lag time $\left(\mathrm{t}_{10 \%}\right)$, i.e. the time to $10 \%$ release in $\mathrm{pH} 6.8$ phosphate buffer, was calculated from the release curves $(\mathrm{n}=3)$ and reported as a detail in the figures together with the relevant coefficient of variation $(\mathrm{CV})$.

\section{Results and discussion}

With the aim of developing a new injection-molded capsule-like container for enteric release, the relevant design and formulation features needed to preliminarily be assessed. The latter were indeed expected to fulfill a number of different requirements, such as the suitability for the oral route, versatility in terms of contents and possibility of filling through established industrial encapsulation processes. At the same time, the desired gastric resistance performance followed by a rapid disintegration/dissolution at intestinal $\mathrm{pH}$ values had to be ensured and merely depend upon the container device irrespective of the conveyed formulation. Furthermore, the IM process should have been feasible and yield molded items with appropriate aspect, technological properties and physical/mechanical stability. As in the micromolding $(\mu \mathrm{IM})$ technique, 
which is currently applied to the production of medical devices and miniaturized electronic parts, a speciallydevised press had to be employed, and the manufacturing was expected to be particularly critical in view of the need for meeting strictly-controlled geometric as well as functional characteristics and maintain them over the shelf-life of the final formulation (Hoyle, 2010; Gomes et al., 2011; Zhang et al., 2012; Heckele and Schomburg, 2004; Giboz et al., 2007; Koç and Özel, 2011). Besides, a strong impact of the operating pressure and thermal history of the material on the dimensional stability of the molded item had to be taken into account.

HPMCAS was chosen as the barrier-forming polymer because of its wide application as an enteric coating material and thermoplastic properties that were already exploited for hot-melt extrusion (HME) (Mehuys et al., 2005). Preliminarily, its softening/melting behavior following heating on hot plate or injection processing (air shot test) and its characteristics after solidification were evaluated, indicating the need for the addition of a plasticizer in order to counteract the glassy nature of the molded material. Among various plasticizers tested (triethyl citrate; dibuthyl sebacate; PEG 400, 1500, 6000 and 20000), PEG 1500 was selected based on the homogeneous aspect of the softened/molten raw materials and the improved mechanical characteristics of the solidified composite. Moreover, HPMCAS blends with PEG 1500 turned out to be the most easily porcessed by the IM press in use. The influence of the plasticizer on the processability of the polymeric formulation and the characteristics of the product was investigated in the 15-35\% (with respect to the amount of polymer) range by means of two-differing molds, i.e. a disk- and a capsule-shaped one, each allowing the nominal thickness of molded items to be varied within a relatively wide range (600, 400 and $200 \mu \mathrm{m}$ or 900,600 and $300 \mu \mathrm{m}$, respectively). The former allows the production of centrally-gated circular disks (diameter $30 \mathrm{~mm}$ ) especially suitable for the evaluation of dimensional changes. With respect to the capsule-shaped mold, though offering several advantages (i.e. production of capsule cap and body within the same cycle, possibility of varying the shell thickness), some limitations in the characteristics of the resulting items could be expected in view of the lateral position of the gate and presence of a mobile insert determining the width of the cavity (Gazzaniga et al., 2011b).

The amount of $15 \%$ of plasticizer turned out to be insufficient, not only on account of the poor flexibility shown by the molded items, but also because only $600 \mu \mathrm{m}$ thick disks could be obtained and no capsular shells at all. Increasing the PEG 1500 content to $25 \%$ was already enough to easily manufacture disks up to $200 \mu \mathrm{m}$ thickness and complete capsular shells of $900 \mu \mathrm{m}$. Only with the highest amount of plasticizer tested, $600 \mu \mathrm{m}$ capsules could be prepared.

When thermoplastics are processed by IM, the dimensions of the molded part change as the part cools. Often, these changes are referred to as either shrinkage or warpage and can be used to predict the appropriate mold geometry (Fisher, 2003). Although shrinkage is based on thermal contraction, other mechanisms may be responsible for dimensional changes after demolding (e.g. inherent stresses, crystallization, mechanical constraint). For example, if residual stresses created by variations in the cooling rate are strong enough to overcome the relevant structural integrity, the part will warp upon ejection from the mold. The control of shrinkage is particularly important in applications requiring tight tolerances. The wall thickness was shown 
to have a major influence on shrinkage that generally turns out increased for thicker parts, because of the variation in a series of parameters such as the holding pressure or the cooling and crystallization rates. In table 3, differences between the thickness of disks and the width of the relevant mold cavity $(600 \mu \mathrm{m})$ are reported along with digital photographs of the molded items immediately after ejection $(t=0)$ and over time $(\mathrm{t}=3$ and $24 \mathrm{~h})$.

Molded HPMCAS disks were proven to increase in thickness immediately after demolding, and no significant influence $(\mathrm{p}<0.1)$ of the amount of plasticizer on this parameter was found. On the contrary, a warp tendency of molded disks was noticed that could be related to the amount of plasticizer in the formulation. In fact, only for the items containing $15 \%$ of PEG 1500, bending was neither observed following demolding nor after storage. This allowed thickness measurements to be performed also $24 \mathrm{~h}$ after manufacturing.

As far as the gastric resistance of PEG25 and PEG35 formulations is concerned, the relevant capsular devices, irrespective of the shell thickness, remained intact in acidic fluid $(\mathrm{pH}=1.2)$ but they were unable to release their contents within $2 \mathrm{~h}$ in phosphate buffer $\mathrm{pH} 6.8$.

These results pointed out some critical issues with respect to the goal of developing a delivery platform for enteric dosage forms based on HPMCAS capsules. In particular, the shrinkage/warpage tendency of the polymeric formulation and the need to shorten the opening time of the device had both to be taken into account. In the plastics industry, the set-up of the melt composition, design of the final mold and adjustment of the operating conditions would have concomitantly be performed (Figure 2). However, because of the inherent complexity of this approach, a formulation study was undertaken at this stage, and molded prototypes were used as screening tools for assessing the effectiveness of the gastric resistance performance. In order to enhance the dissolution/disintegration rate of the capsular device at intestinal $\mathrm{pH}$ values, $i$ ) release modifiers, the channelling action of which could be attributed to the inherent solubility or swelling properties, and $i$ ) buffering salts (dipotassium hydrogen phosphate and sodium hydrogen carbonate), potentially suitable for increasing the microenvironmental $\mathrm{pH}$ of the surrounding fluids, were considered. The addition of soluble pore formers or disintegrants (e.g. polyvinylpyrrolidone and croscarmellose sodium, respectively) to film-coating suspensions of $\mathrm{pH}$-responsive polymers was already suggested with the aim of improving the pulsatile release of drugs to the ileo-colonic region (Zhang et al., 2007; Schellekens et al., 2008). Moreover, a double-coated enteric system consisting of an inner layer of Eudragit ${ }^{\circledR}$ L or $S$ neutralized with organic acids and an outer conventional coating of the same polymer was recently proposed (Liu et al., 2009; Liu and Basit, 2010; Liu et al., 2010). Such a device was subject to a fast and consistent disintegration after stomach emptying (around $30 \mathrm{~min}$ in vivo disintegration time).

245 The types and/or amounts of adjuvants were selected by preliminary heating and/or molding tests. In this respect, browning phenomena occurred at operating temperatures on polymeric samples containing either the phosphate or carbonate salt, thus pointing out possible stability issues for molded items. A polyvinyl alcoholpolyethylene glycol graft copolymer (Kollicoat ${ }^{\circledR}$ IR), generally employed as the film-forming polymer for immediate-release coated dosage forms or as a binder in fast-dissolving tablets, was selected as the soluble 
pore former. Although characterized by a glassy-rubbery transition temperature $(\mathrm{Tg})$ around $200{ }^{\circ} \mathrm{C}$, when Kollicoat ${ }^{\circledR}$ IR was worked in admixture with plasticized HPMCAS, a homogeneous molded material was obtained already at the lowest operating temperatures. Among the disintegrants tested (starch and cellulose derivatives), sodium starch glycolate (Explotab ${ }^{\circledR} \mathrm{CLV}$ ) was shown to exert no negative impact on the processability of the polymeric substrate and rather improve the dimensional stability of molded items as expected from solid fillers (Zweifel et al., 2009). As far as the polymer/plasticizer ratio in the polymeric formulations with the release modifiers is concerned, $25 \%$ of PEG 1500 with respect to the amount of HPMCAS was preferred because of the acceptable balance between processability of the polymeric substrate and dimensional changes of the product that was previously obtained.

Disks of 200,400 and $600 \mu \mathrm{m}$ containing $30 \%$ by weight of either the soluble pore former or the disintegrant selected were obtained, whereas in no case intact and complete capsular shells with thickness other than 900 $\mu \mathrm{m}$ were produced. The manufacturing of $200 \mu \mathrm{m}$ disks with the KIR formulation was especially critical, thus providing brittle and often damaged items that could not withstand characterization. SEM photomicrographs helped highlight the surface and structure characteristics of molded items containing Kollicoat ${ }^{\circledR}$ IR or Explotab ${ }^{\circledR}$ CLV as compared with HPMCAS ones (Figure 3). In particular, solid particles

265 distributed throughout the cross-section of the disintegrant-containing item are clearly evident.

In Figure 4 the release profiles of capsular devices containing a powder tracer and the relevant $\mathrm{t}_{10 \%}$ values in pH 6.8 buffer are reported.

Both the Kollicoat ${ }^{\circledR}$ IR- and Explotab ${ }^{\circledR}$ CLV-based capsular systems were demonstrated able to withstand the acidic medium ( $\mathrm{pH}$ 1.2) for two hours, confirming that the release modifiers were efficiently embedded in the molded polymeric matrix. In pH 6.8 buffer a lag time of about $1,5 \mathrm{~h}$ prior to the break-up of capsular devices and release of the conveyed powder was observed, which was slighlty shorter for the disintegrantcontaining shell. Indeed, a minor diffusive release phase was shown by the capsular system with the soluble pore former. In order to evaluate the influence of the polymeric barrier thickness, the molded disks made of HPMCAS blends with Kollicoat ${ }^{\circledR}$ IR and Explotab ${ }^{\circledR}$ CLV were used. For this purpose, a testing method analogous to the compendial dissolution test for transdermal patches was set up. The amount of tracer assayed in the acceptor fluid, which was separated from the donor powder reservoir by molded disks of differing thicknesses (Figure 1), was plotted versus time (Figure 5). As in the release profiles of capsules, a lag time prior to the rupture of the polymeric barrier was observed. Only in the case of the EXP formulation, $\mathrm{t}_{10 \%}$ values showed a tendency to decrease when reducing the thickness of disks to $200 \mu \mathrm{m}$. Indeed, a small amount of tracer was recovered in the acidic medium when one of the $200 \mu \mathrm{m}$ disks was tested thus pointing out the possible existence of a thickness threshold for gastric resistance failure. The polymeric barrier containing Kollicoat ${ }^{\circledR}$ IR confirmed a less prompt break-up, with an initial diffusive release phase. Moreover, in the case of $400 \mu \mathrm{m}$ disks, $\mathrm{t}_{10 \%}$ values obtained from the disintegrant-containing formulation were significantly $(\mathrm{p}<0.1)$ lower as compared with those relevant to the KIR one, thus indicating that a more efficient mechanism would promote the polymer disintegration/dissolution in $\mathrm{pH} 6.8$ buffer. The overall results obtained from capsular devices and disks containing pore formers indicated that the erosion of the 
HPMCAS matrix would in any case be triggered by the $\mathrm{pH}$ change, as this allows the medium to reach the adjuvants incorporated. Afterwards, the soluble polymer Kollicoat ${ }^{\circledR}$ IR may aid the solvent penetration only, while the disintegrant could also promote the formation of cracks in the polymeric barrier thereby reducing its resistance to rupture (Schellekens et al., 2008). The latter hypothesis was confirmed by photomicrographs of partially eroded molded items (i.e. disks exposed to $\mathrm{pH} 6.8$ buffer for 120 minutes and dried before being analysed) (Figure 6). In fact, the disintegrant particles embedded in the polymeric matrix seem to be located within hollows that are larger than the dried particle itself and show tears on their edges. Such hollows and relevant tears may have formed because of the swelling of Explotab ${ }^{\circledR}$ CLV upon exposure to the aqueous fluid.

According to the above discussed mechanisms, the ability of the soluble pore former to increase the extent of solvent penetration could improve the efficiency of the disintegrant. In this respect, confirmatory results were preliminarily obtained comparing the performance of $900 \mu \mathrm{m}$ thick capsular shells containing blends of Kollicoat ${ }^{\circledR}$ IR and Explotab ${ }^{\circledR}$ CLV (10\% and $20 \%$, respectively, and vice versa) (Figure 7) with that of shells based on a single component (Kollicoat ${ }^{\circledR}$ IR or Explotab ${ }^{\circledR}$ CLV). Indeed, devices prepared from the 2EXP1KIR formulation in which $10 \%$ of the disintegrant was replaced with the soluble polymer showed the shortest lag time. On the contrary, only $10 \%$ of disintegrant in the shell composition seemed not enough to establish the cracking mechanism.

In order to undertake the development of gastric resistant container-like devices, the impact of the shell thickness on the release performance needed to be more in depth investigated. Therefore, some attempts were made at improving the IM processability of adjuvant-containing HPMCAS formulations. As expected, by adjusting the polymer to plasticizer ratio (increasing the amount of PEG 1500 to $35 \%$ on dry polymer), $600 \mu \mathrm{m}$ capsular shells were manufactured containing $30 \%$ of Explotab ${ }^{\circledR}$ CLV. The relevant devices showed adequate gastric resistance in the acidic medium and a lag phase of less than $1 \mathrm{~h}$ in pH 6.8 buffer (Figure 8). Thus, the possibility of obtaining an earlier break-up of enteric capsule-like devices by decreasing the shell thickness was confirmed, and this could represent the proper approach to the achievement of the desired release behavior.

\section{Conclusions}

315 The use of capsular containers suitable for conveying different types of drug formulations and determining the relevant release performance was recently proposed; for the manufacturing of such devices, IM technique was exploited because of the advantages it would offer in terms of versatility (dimensions, composition and shape or shape details), scalability and patentability of the relevant products. In this work, the development of enteric soluble capsules based on HPMCAS was approached. The feasibility of the manufacturing process with a polymeric formulation containing a plasticizer and a release modifier or mixtures of different types of release modifiers (a soluble pore former and a disintegrant, i.e. Kollicoat ${ }^{\circledR}$ IR and Explotab ${ }^{\circledR}$ CLV, respectively) was assessed. This basic composition showed promising results with respect to a possible fine tuning of the thickness and mechanical characteristics of the capsule shell, thus allowing the gastric 
resistance performance to be defined. Accordingly, the development process would be worth being pursued by finalizing the formulation parameters, designing a dedicated mold and setting up suitable operating conditions.

\section{Acknowledgments}

The support of Consortium TEFARCO Innova and Regione Lombardia, Fondo Sociale Europeo is gratefully acknowledged.

\section{References}

Bianchini, R., Resciniti, M., Vecchio, C., 1991. Technological evaluation of aqueous enteric coating systems with and without insoluble additives. Drug Dev. Ind. Pharm. 17, 1779-1794.

Blubaugh, F.C., Zapapas, J.R., Sparks, M.C., 1958. An enteric compression coating. I. In vitro studies. J. Am. Pharm. Assoc. 47, 857-862.

Cerea, M., Foppoli, A., Maroni, A., Palugan, L., Zema, L., Sangalli, M.E., 2008b. Dry coating of soft gelatine capsules with HPMCAS. Drug Dev. Ind. Pharm. 34, 1196-1200.

Cerea, M., Zema, L., Palugan, L., Gazzaniga, A., 2008a. Recent developments in dry coating. Pharm. Tech. Eur. 20, 40-44.

Cole, E.T., Scott, R.A., Connor, A.L., Wilding, I.R., Petereit, H.-U., Schminke, C., Beckert, T., Cadé, D., 2002. Enteric coated HPMC capsules designed to achieve intestinal targeting. Int. J. Pharm. 231, 83-95.

Davis, S.S., 1985. The design and evaluation of controlled release systems for the gastro-intestinal tract. J. Control. Release 2, 27-38.

Dulin, W., 2010. Oral targeted drug delivery systems: enteric coating, in: Wen, H., Park, K. (Eds.), Oral controlled release formulation design and drug delivery: theory to practice. John Wiley \& Sons, New Jersey, pp. 205-224.

Eith, L., Stepto, R.F.T., Tomka, I., Wittwer, F., 1986. The injection-moulded capsule. Drug Dev. Ind. Pharm. 12, 2113-2126.

350 Felton, L.A., Haase, M.M., Shah, N.H., Zhang, G., Infeld, M.H., Malick, A.W., McGinity, J.W., 1995. Physical and enteric properties of soft gelatin capsules coated with Eudragit ${ }^{\circledR}$ L 30 D-55. Int. J. Pharm. 113, $17-24$.

Felton, L.A., McGinity, J.W., 1996. The influence of tablet hardness and tablet hydrophobicity on the adhesive properties of an acrylic resin copolymer. Pharm. Dev. Technol. 1, 381-389. 
Felton, L.A., McGinity, J.W., 2003. Enteric film coating of soft gelatin capsules. Drug Deliv. Tech. 3, 48-51.

Fischer, J.M., 2003. Handbook of molded part shrinkage and warpage. William Andrew Inc., New York.

Fukui, E., Miyamura, N., Kobayashi, M., 2001a. Effect of magnesium stearate or calcium stearate as additives on dissolution profiles of diltiazem hydrochloride from press-coated tablets with hydroxypropylmethylcellulose acetate succinate in the outer shell. Int. J. Pharm. 216, 137-146.

Fukui, E., Miyamura, N., Yoneyama, T., Kobayashi, M., 2001b. Drug release from and mechanical properties of press-coated tablets with hydroxypropylmethylcellulose acetate succinate and plasticizers in the outer shell. Int. J. Pharm. 217, 33-43.

Gazzaniga, A., Cerea, M., Cozzi, A., Foppoli, A., Maroni, A., Zema, L., 2011b. A novel injection-molded capsular device for oral pulsatile delivery based on swellable/erodible polymers. AAPS Pharm. Sci. Tech. 12, 295-303.

Gazzaniga, A., Cerea, M., Cozzi, A., Foppoli, A., Tavella, G., Zema, L., 2011a. Pharmaceutical dosage forms for time-specific drug delivery. EP 2317988.

Gazzaniga, A., Foppoli, A., Maroni, A., Cozzi, A., Macchi, E., Cerea, M., 2011c. Injection-molded capsular device for oral pulsatile delivery: an in vivo evaluation. $38^{\text {th }}$ CRS annual meeting \& exposition July 30 August 3, National Harbor, Maryland.

Gazzaniga, A., Giordano, F., Sangalli, M.E., Zema, L., 1994. Oral colon-specific drug delivery: design strategies. STP Pharma Pratiques 4, 336-343.

Gazzaniga, A., Maroni, A., Sangalli, M.E., Zema, L., 2006. Time-controlled oral delivery systems for colon targeting. Expert Opin. Drug Deliv. 3, 583-597.

375 Giboz, J., Copponnex, T., Mèle, P., 2007. Microinjection molding of thermoplastic polymers: a review. J. Micromech. Microeng. 17, R96-R109.

Gomes, M.E., Ribeiro, A.S., Malafaya, P.B., Reis, R.L., Cunha, A.M., 2011. A new approach based on injection moulding to produce biodegradable starch-based polymeric scaffolds: morphology, mechanical and degradation behavior. Biomaterials 22, 883-889.

Heckele, M., Schomburg, W.K., 2004. Review on micro molding of thermoplastic polymers. J. Micromech. Microeng. 14, R1-R14.

Hoyle, R., 2010. Manufacturing components for a micro litre drug delivery system. Eur. Med. Device. Technol. 1.

Kablitz, C.D., Harder, K., Urbanetz, N.A., 2006. Dry coating in a rotary fluid bed. Eur. J. Pharm. Sci. 27, 
Koç, M., Özel, T. (Eds.) 2011. Micro-manufacturing: design and manufacturing of micro-products. John Wiley \& Sons publication, New Jersey.

Lau, K.K.S., Gleason, K.K., 2007. All-dry synthesis and coating of methacrylic acid copolymers for controlled release. Macromol. Biosci. 7, 429-434.

Liu, F., Basit, A.W., 2010. A paradigm shift in enteric coating: achieving rapid release in the proximal small intestine of man. J. Control. Release 147, 242-245.

Liu, F., Lizio, R., Meier, C., Petereit, H.-U., Blakey, P., Basit, A.W., 2009. A novel concept in enteric coating: a double-coating system providing rapid drug release in the proximal small intestine. J. Control. Release 133, 119-124.

Liu, F., Morenoa, P., Basit, A.W, 2010. A novel double-coating approach for improved pH-triggered delivery to the ileo-colonic region of the gastrointestinal tract. Eur. J. Pharm. Biopharm. 74, 311-315.

McConnell, E.L., Fadda, H.M., Basit, A.W., 2008. Gut instincts: explorations in intestinal physiology and drug delivery. Int. J. Pharm. 364, 213-226.

McGinity, J.W., Felton, L.A., (Eds.) 2008. Aqueous polymeric coatings for pharmaceutical dosage forms, third ed., Informa Healthcare, New York.

Mehuys, E., Remon, J.-P., Vervaet, C., 2005. Production of enteric capsules by means of hot-melt extrusion. Eur. J. Pharm. Sci. 24, 207-212.

Nastruzzi, C., Cortesi, R., Esposito, E., Genovesi, A., Spadoni, A., Vecchio, C., Menegatti, E., 2000. Influence of formulation and process parameters on pellet production by powder layering technique. AAPS 405 Pharm. Sci. Tech. 1, E9.

Obara, S., Maruyama, N., Nishiyama, Y., Kokubo, H., 1999. Dry coating: an innovative enteric coating method using a cellulose derivative. Eur. J. Pharm. Biopharm. 47, 51-59.

Porter, S.C., Felton, L.A., 2010. Techniques to assess film coatings and evaluate film-coated products. Drug Dev. Ind. Pharm. 36, 128-142.

410 Rosato, D.V., Rosato, D.V., Rosato, M.G., 2000. Injection Molding Handbook, third ed., Kluwer Academic Publishers, Massachussets.

Schellekens, R.C.A., Stellaard, F., Mitrovic, D., Stuurman, F.E., Kosterink, J.G.W., Frijlink, H.W., 2008. Pulsatile drug delivery to ileo-colonic segments by structured incorporation of disintegrants in $\mathrm{pH}$-responsive polymer coatings. J. Control. Release 132, 91-98. 
415 Siepmann, F., Siepmann, J., Walther, M., MacRae, R., Bodmeier, R., 2006. Aqueous HPMC-AS coatings: effect on formulation and processing parameters on drug release and mass transport mechanism. Eur. J. Pharm. Biopharm. 63, 262-269.

Vilivalam, V.D., Illum, L., Iqbal, K., 2000. Starch capsules: an alternative system for oral drug delivery. Pharm. Sci. Technol. Today 3, 64-69.

420 Zema, L., Loreti, G., Melocchi, A., Maroni, A., Gazzaniga, A., 2012. Injection Molding and its application to drug delivery. J. Control. Release doi:10.1016/j.jconrel.2012.01.001.

Zhang, X., Wang, Y., Wang, J., Wang, Y., Li, S., 2007. Effect of pore former on the properties of casted film prepared from blends of Eudragit ${ }^{\circledR}$ NE 30D and Eudragit ${ }^{\circledR}$ L 30 D-55. Chem. Pharm. Bull. 55, 1261-1263.

Zhang, Y., Brown, K., Siebenaler, K., Determan, A., Dohmeier, D., Hansen, K., 2012. Development of 425 lidocaine-coated microneedle product for rapid, safe, and prolonged local analgesic action. Pharm. Res. 29, $170-177$.

Zweifel, H., Maier, R.D., Schiller, M., (Eds.) 2009. Plastics additives handbook, sixth ed., Hanser, Ohio. 
Table 1 Composition ( $\%$ by weight) of molded formulations

\begin{tabular}{|c|c|c|c|c|}
\cline { 2 - 5 } \multicolumn{1}{c|}{} & Polymer & Plasticizer & \multicolumn{2}{c|}{ Release modifier } \\
\hline Code & HPMCAS & PEG 1500 & Explotab $^{\circledR}$ CLV & Kollicoat $^{\circledR}$ IR \\
\hline PEG15 & 87 & 13 & - & - \\
\hline PEG25 & 80 & 20 & - & - \\
\hline PEG35 & 74 & 26 & - & - \\
\hline EXP & 60 & 15 & 25 & - \\
\hline EXPPEG35 & 55 & 20 & 25 & - \\
\hline KIR & 60 & 15 & - & 25 \\
\hline 1EXP2KIR & 60 & 15 & 8.5 & 16.5 \\
\hline 2EXP1KIR & 60 & 15 & 16.5 & 8.5 \\
\hline
\end{tabular}


Table 2 IM operating conditions

\begin{tabular}{|l|c|c|}
\cline { 2 - 3 } \multicolumn{1}{c|}{} & Disk & Capsule \\
\cline { 2 - 3 } \multicolumn{1}{c|}{} & & \\
\hline Plasticating chamber temperature $\left({ }^{\circ} \mathrm{C}\right)$ & $120-160$ & $140-165$ \\
\hline Injecting temperature $\left({ }^{\circ} \mathrm{C}\right)$ & $130-170$ & $143-168$ \\
\hline Nozzle temperature $\left({ }^{\circ} \mathrm{C}\right)$ & $140-180$ & $145-170$ \\
\hline Charge $(\mathrm{mm})$ & $4.5-11$ & $6-20$ \\
\hline First-injection pressure $($ bar $)$ & $20-90$ & $60-110$ \\
\hline First-injection time $(\mathrm{sec})$ & 0.8 & $0.8-20$ \\
\hline First-injection rate $(\%)$ & $40-90$ & $5-85$ \\
\hline Second-injection pressure $($ bar $)$ & $15-70$ & $35-65$ \\
\hline Second-injection time $(\mathrm{sec})$ & 0.3 & $0.3-10$ \\
\hline Second-injection rate $(\%)$ & $30-70$ & $40-75$ \\
\hline Cooling temperature $\left({ }^{\circ} \mathrm{C}\right)$ & 15 & $15-25$ \\
\hline Cooling pressure $($ bar $)$ & 60 & $60-90$ \\
\hline Cooling time $($ sec $)$ & 2.5 & 10 \\
\hline Opening rate $(\%)$ & $20-40$ & 40 \\
\hline
\end{tabular}


Table 3 Changes in thickness and aspect of $600 \mu \mathrm{m}$ disks over $24 \mathrm{~h}$ from manufacturing

\begin{tabular}{|c|c|c|c|c|c|}
\hline \multirow{2}{*}{ Code } & \multicolumn{2}{|c|}{$\begin{array}{c}\Delta \text { thickness } \\
\mu \mathrm{m}(\mathrm{CV})\end{array}$} & \multicolumn{3}{|c|}{ Pictures } \\
\hline & $t=0$ & $\mathrm{t}=24 \mathrm{~h}$ & $t=0$ & $\mathrm{t}=3 \mathrm{~h}$ & $t=24 h$ \\
\hline PEG 15 & $43(7)$ & $47(8)$ & & & \\
\hline PEG 25 & $55(23)$ & n.d. & E & & \\
\hline PEG 35 & $35(21)$ & n.d. & A & & \\
\hline
\end{tabular}

n.d. = not determined because of disk deformation 
Figure 1 Outline of the system for the evaluation of disk gastric resistance.

Figure 2 Interrelated steps involved in the development of the molded device.

Figure 3 Photomicrographs of the surface $(a, b$ and $c)$ and cross-section $\left(a_{t}, b_{t}\right.$ and $\left.c_{t}\right)$ of molded HPMCASbased $400 \mu \mathrm{m}$ disks, as such ( $a$ and $a_{t}$ ) or containing $30 \%$ by weight of a release modifier (Kollicoat ${ }^{\circledR}$ IR: $b$ and $b_{t}$ or Explotab ${ }^{\circledR}$ CLV: c and $c_{t}$ ).

Figure 4 Release profiles of $900 \mu \mathrm{m}$ thick enteric capsular devices containing $30 \%$ by weight of a release modifier (top: Kollicoat ${ }^{\circledR} \mathrm{IR}$, bottom: Explotab ${ }^{\circledR} \mathrm{CLV}$ ); mean $\mathrm{t}_{10 \%}(\mathrm{~min})$ in $\mathrm{pH} 6.8$ buffer and relevant CV highlighted in tables.

Figure 5 Amount (\%) of tracer in the acceptor fluid separated from the donor compartment by molded HPMCAS disks of differing thicknesses $(600,400$ and $200 \mu \mathrm{m}$ for a, $\mathrm{b}$ and c, respectively) containing $30 \%$ by weight of a release modifier (Kollicoat ${ }^{\circledR}$ IR on the left and Explotab ${ }^{\circledR}$ CLV on the right) $v s$ time profiles; mean $\mathrm{t}_{10 \%}$ (min) in $\mathrm{pH} 6.8$ buffer and relevant $\mathrm{CV}$ highlighted in tables.

Figure 6 Photomicrographs at different magnification (110, 400, 800, $2000 \mathrm{X}$ for a, b, c, and c', respectively) of the surface of HPMCAS-based $400 \mu \mathrm{m}$ disks containing $30 \%$ of Explotab ${ }^{\circledR}$ CLV after exposure to pH 6.8 buffer; c' is a detail from photomicrograph c.

Figure 7 Release profiles of $900 \mu \mathrm{m}$ thick enteric capsular devices containing 30\% by weight of a mixture of

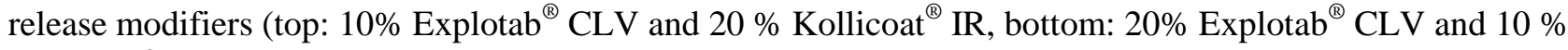
Kollicoat $^{\circledR} \mathrm{IR}$ ); mean $\mathrm{t}_{10 \%}$ (min) in pH 6.8 buffer and relevant $\mathrm{CV}$ highlighted in tables.

Figure 8 Release profiles of $600 \mu \mathrm{m}$ thick enteric capsular devices containing $30 \%$ by weight of Explotab ${ }^{\circledR}$ $\mathrm{CLV}$; mean $\mathrm{t}_{10 \%}(\mathrm{~min})$ in $\mathrm{pH} 6.8$ buffer and relevant $\mathrm{CV}$ highlighted in tables. 
Click here to download high resolution image

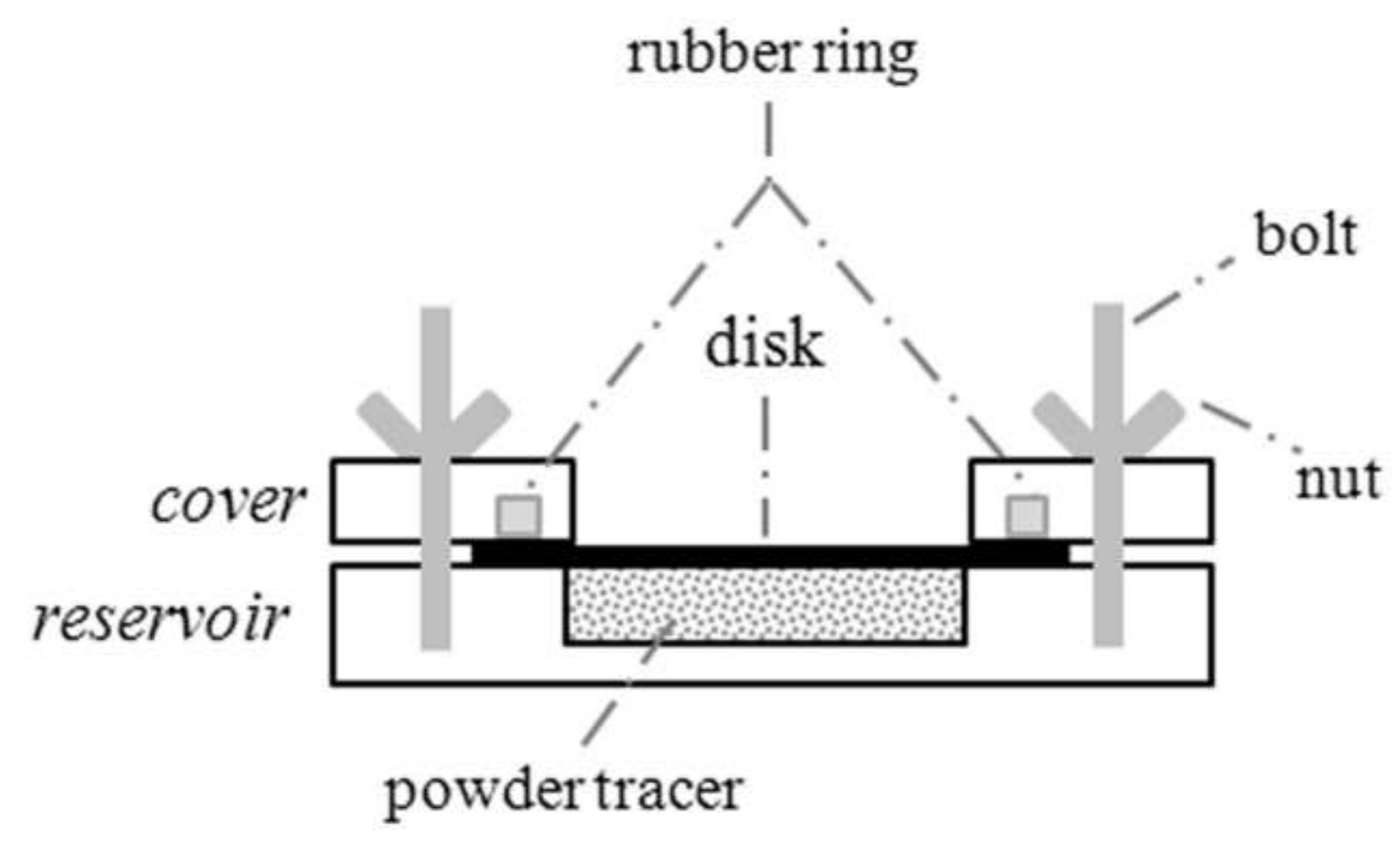




\section{FORMULATION}

\section{(performance/processability)}

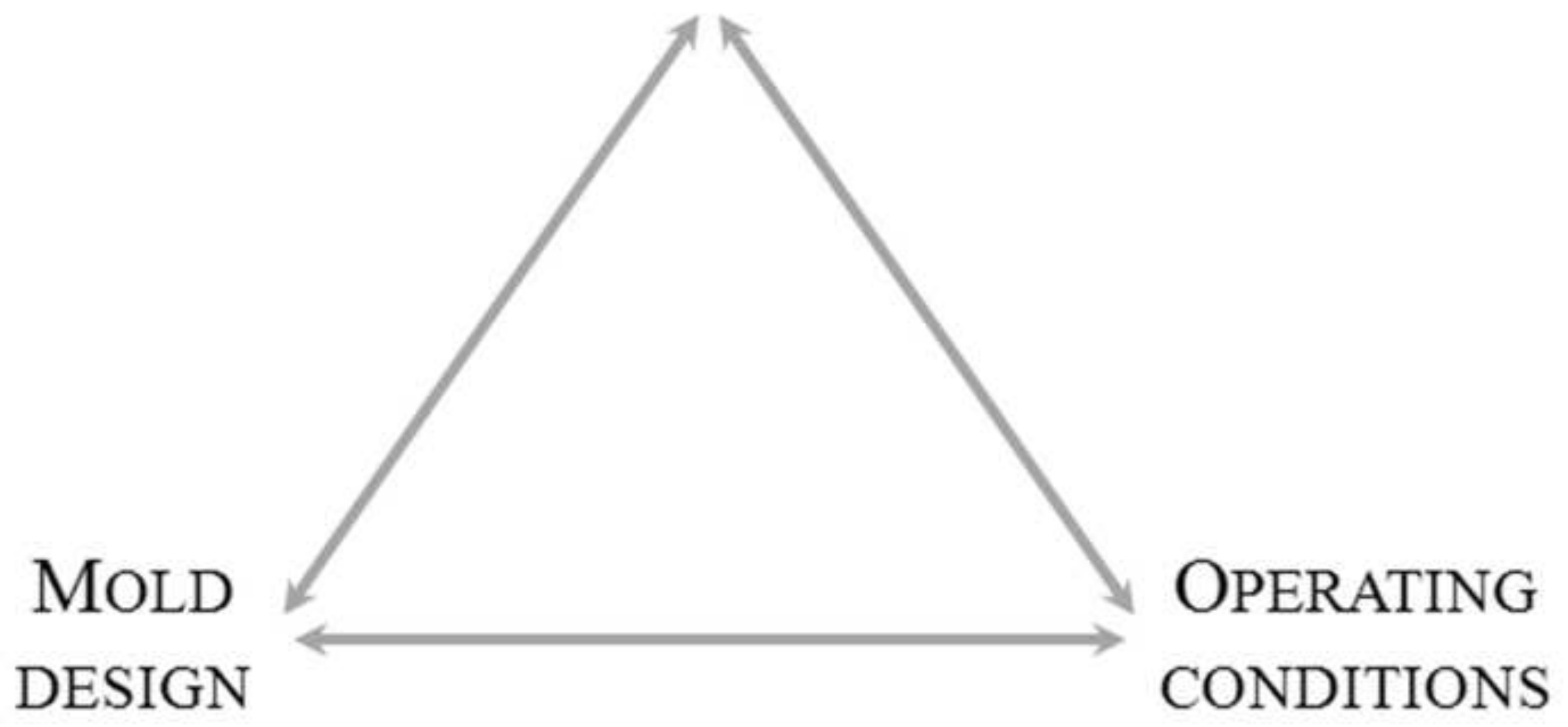



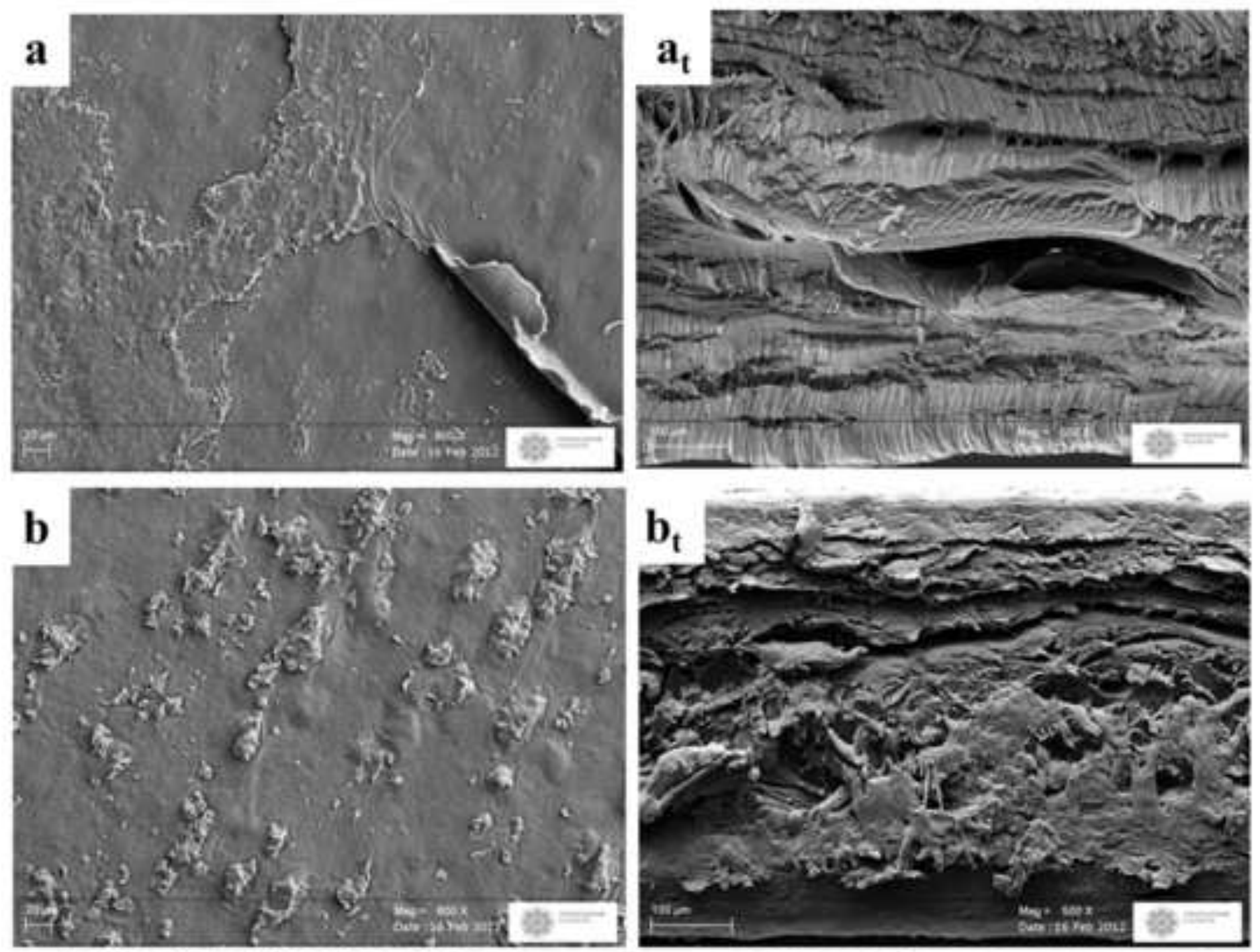

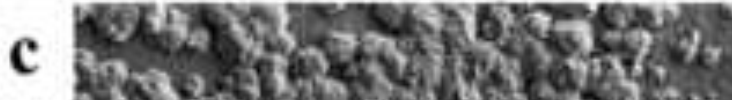
mas.4.
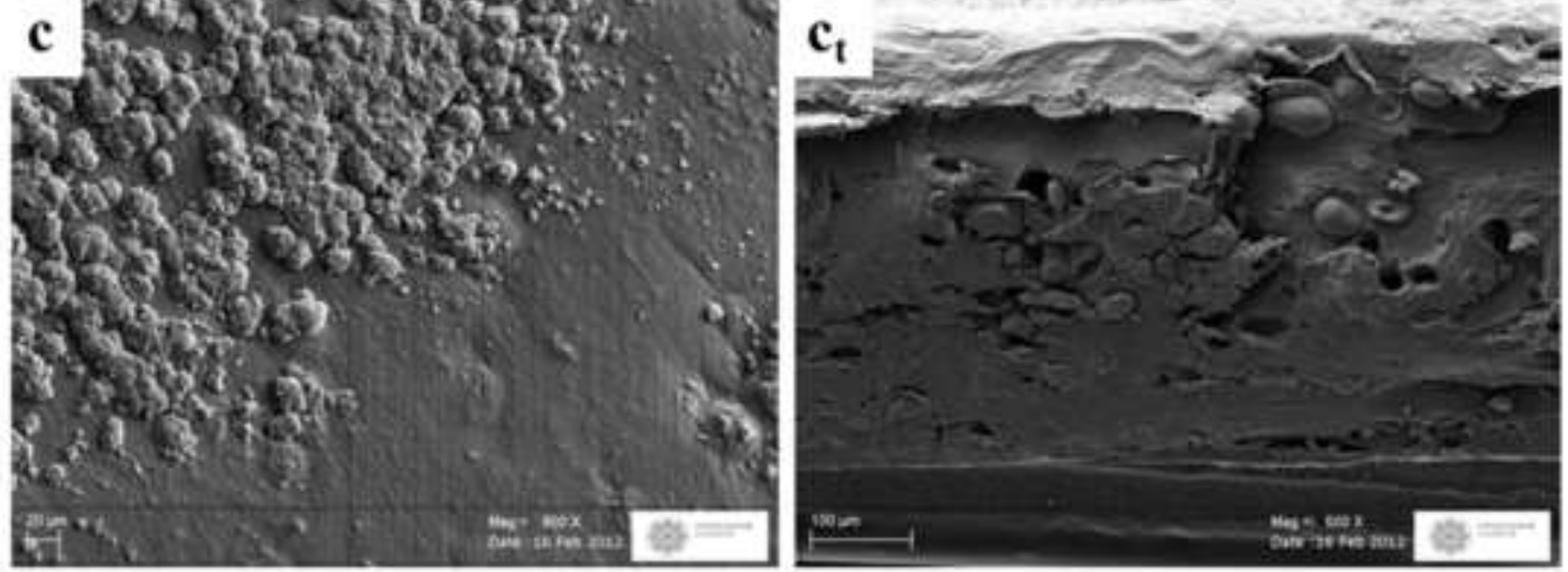
Figure 4
Click here to download high resolution image

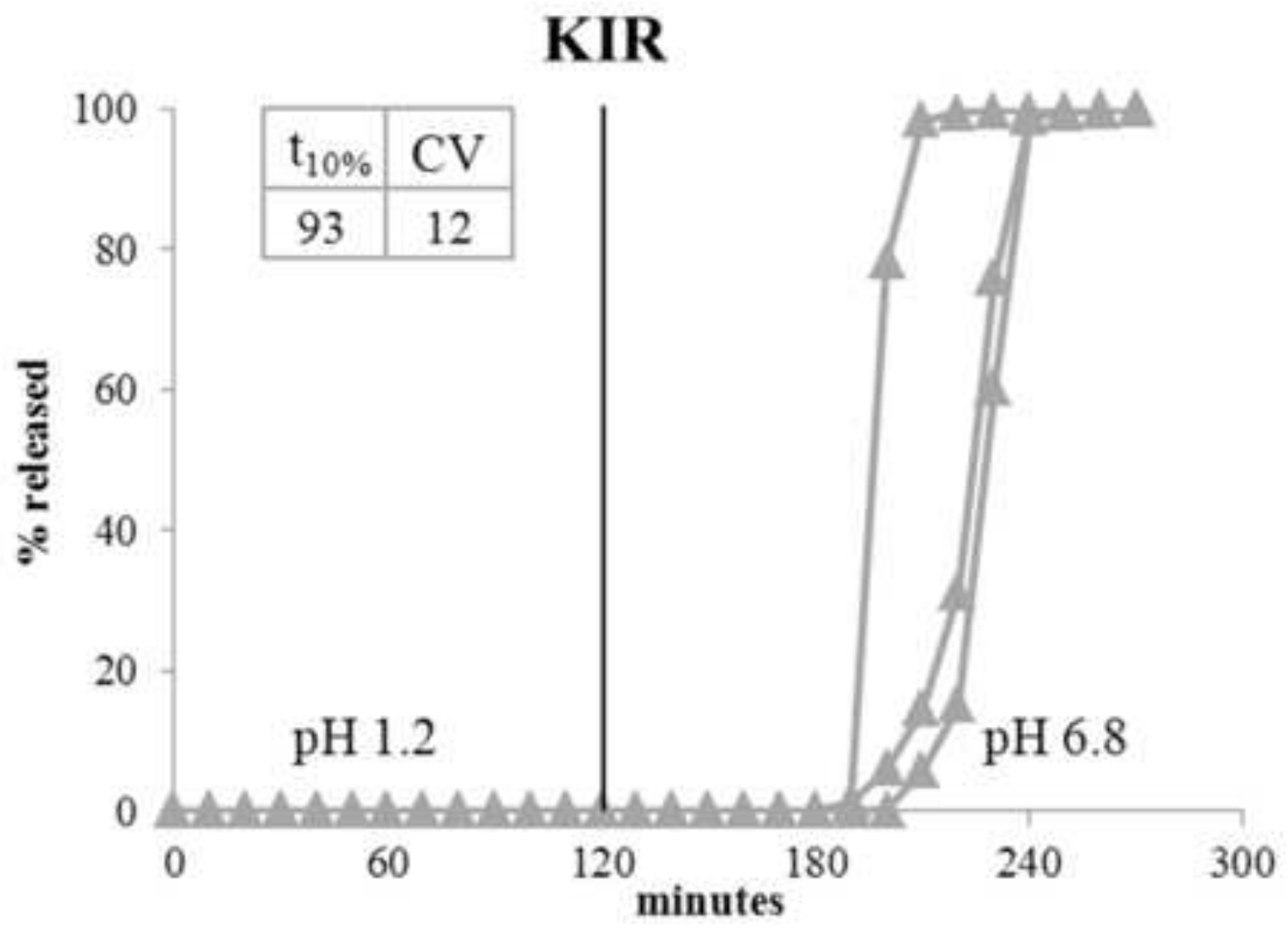

EXP

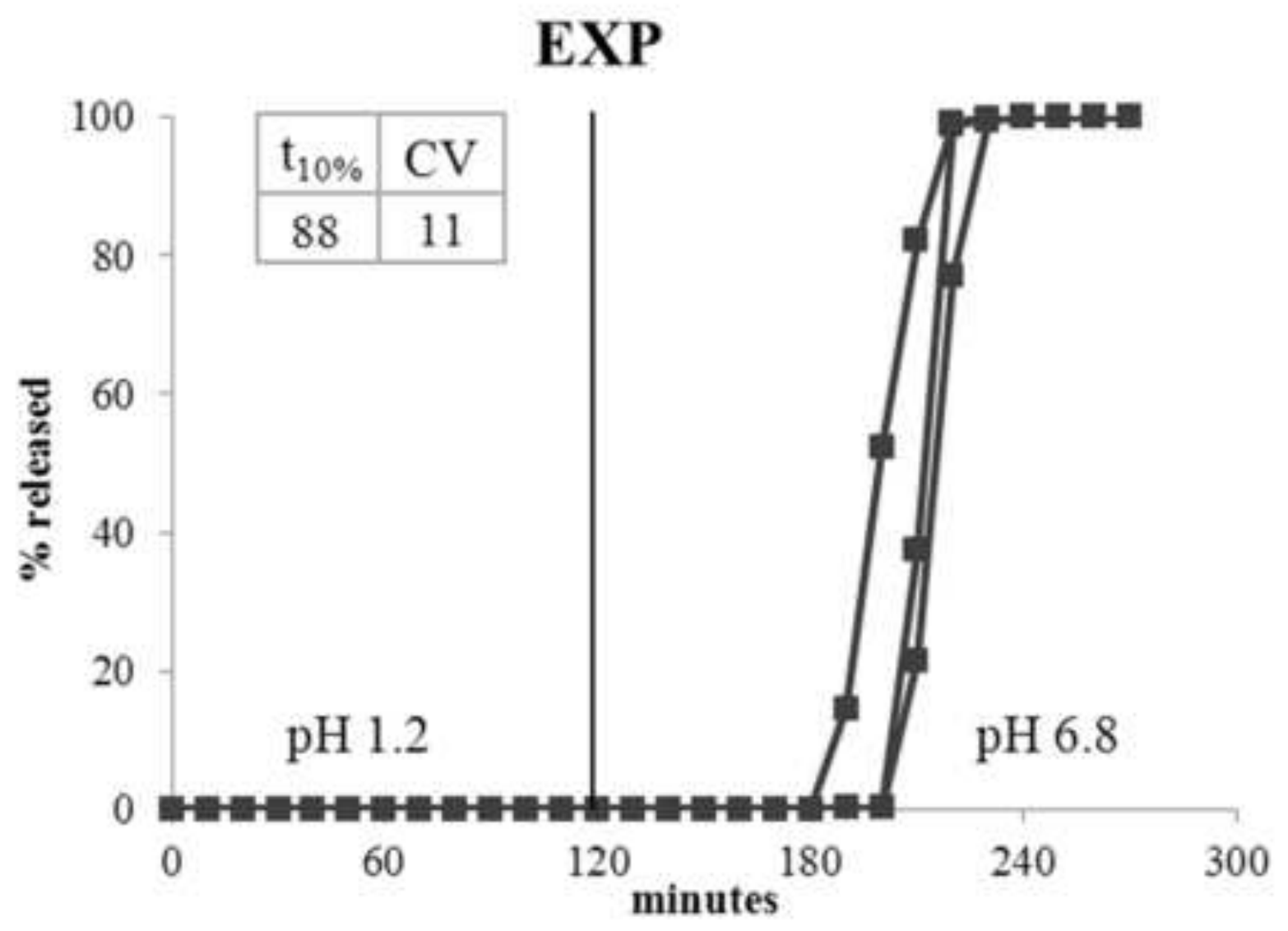


Click here to download high resolution image

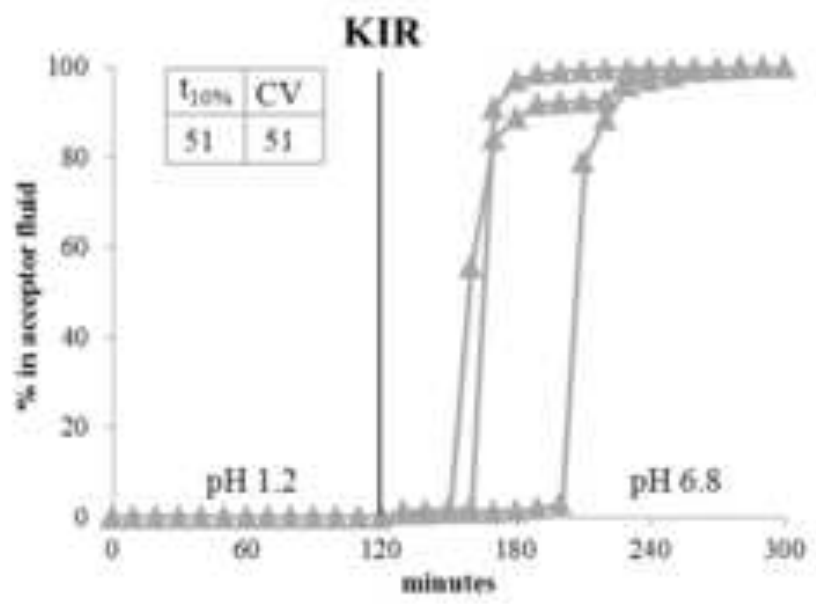

a
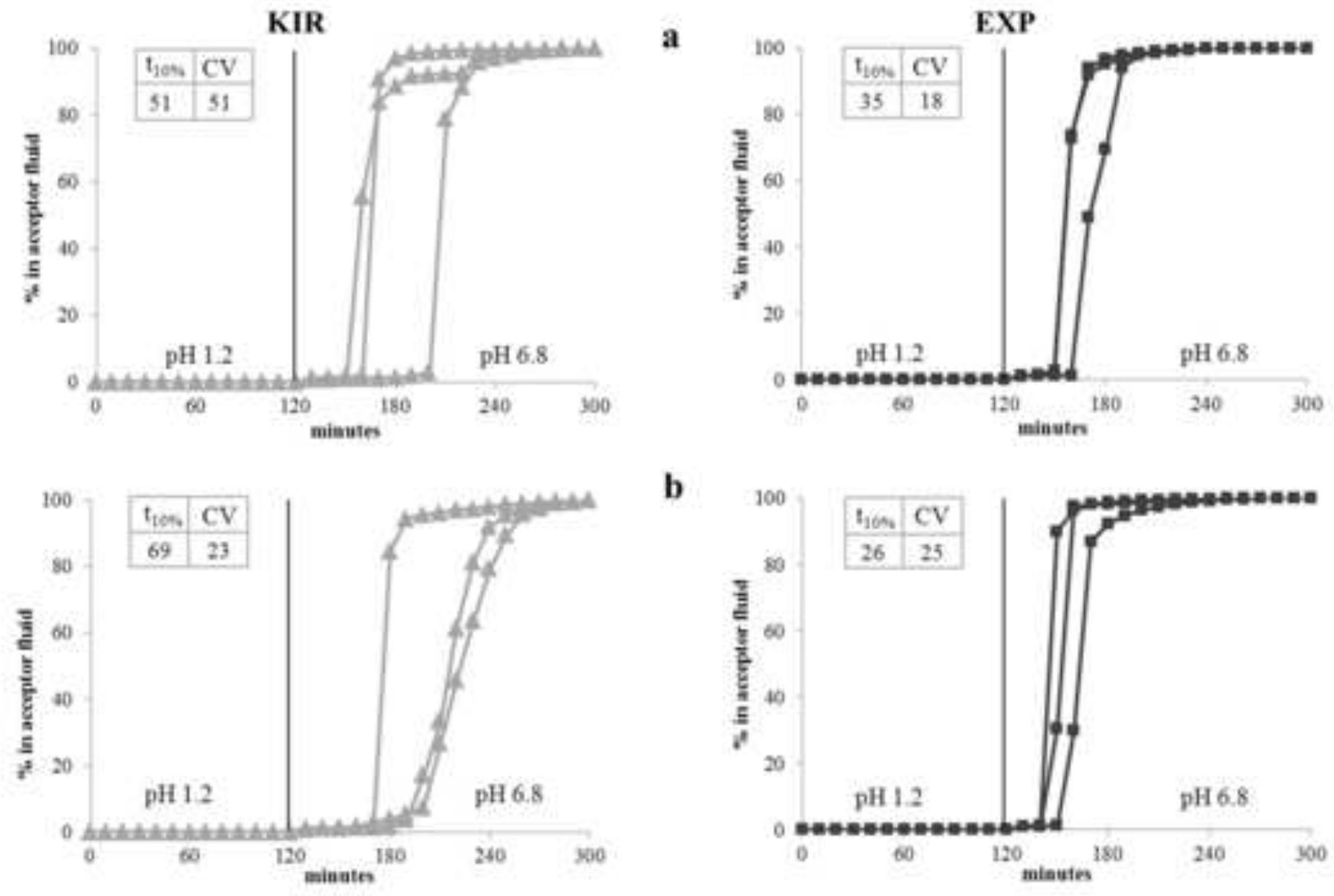

b

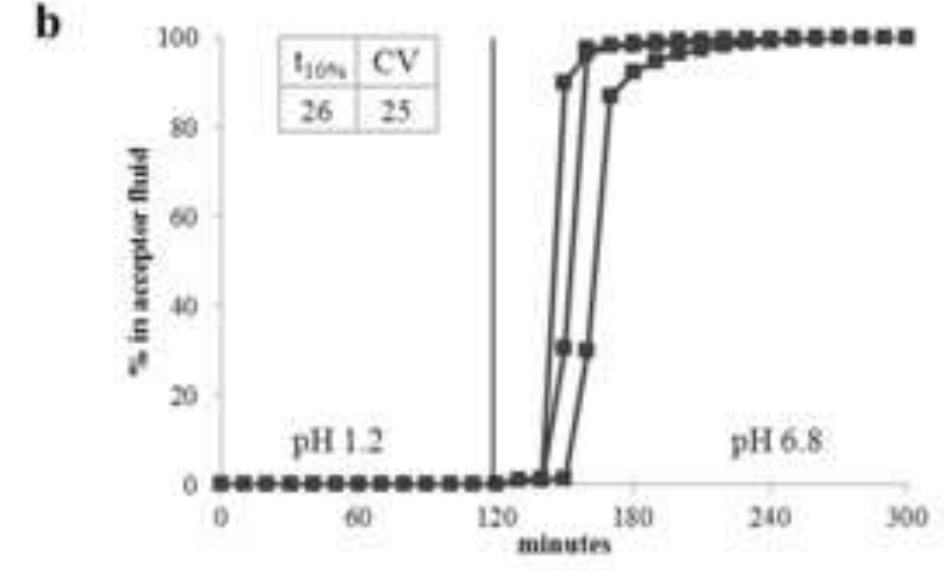

c

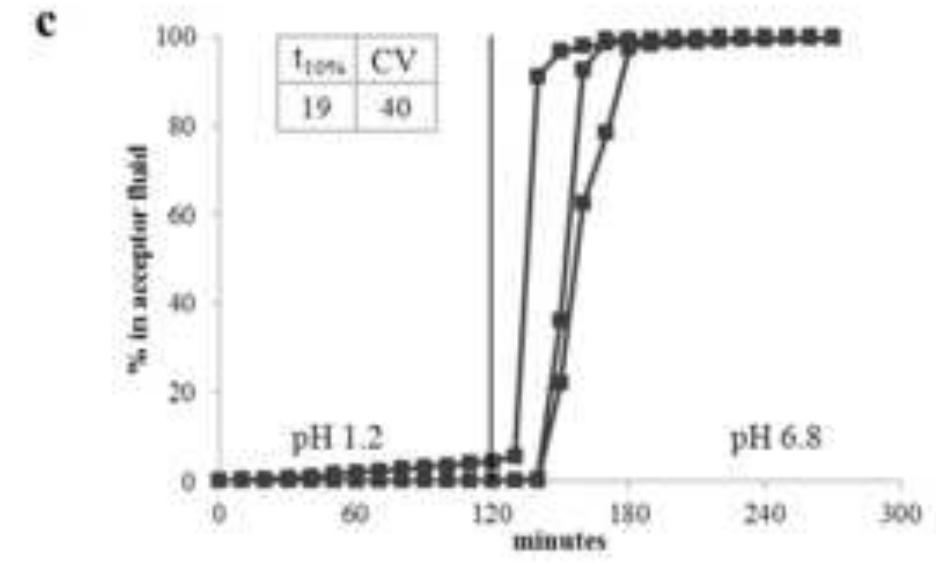


Click here to download high resolution image
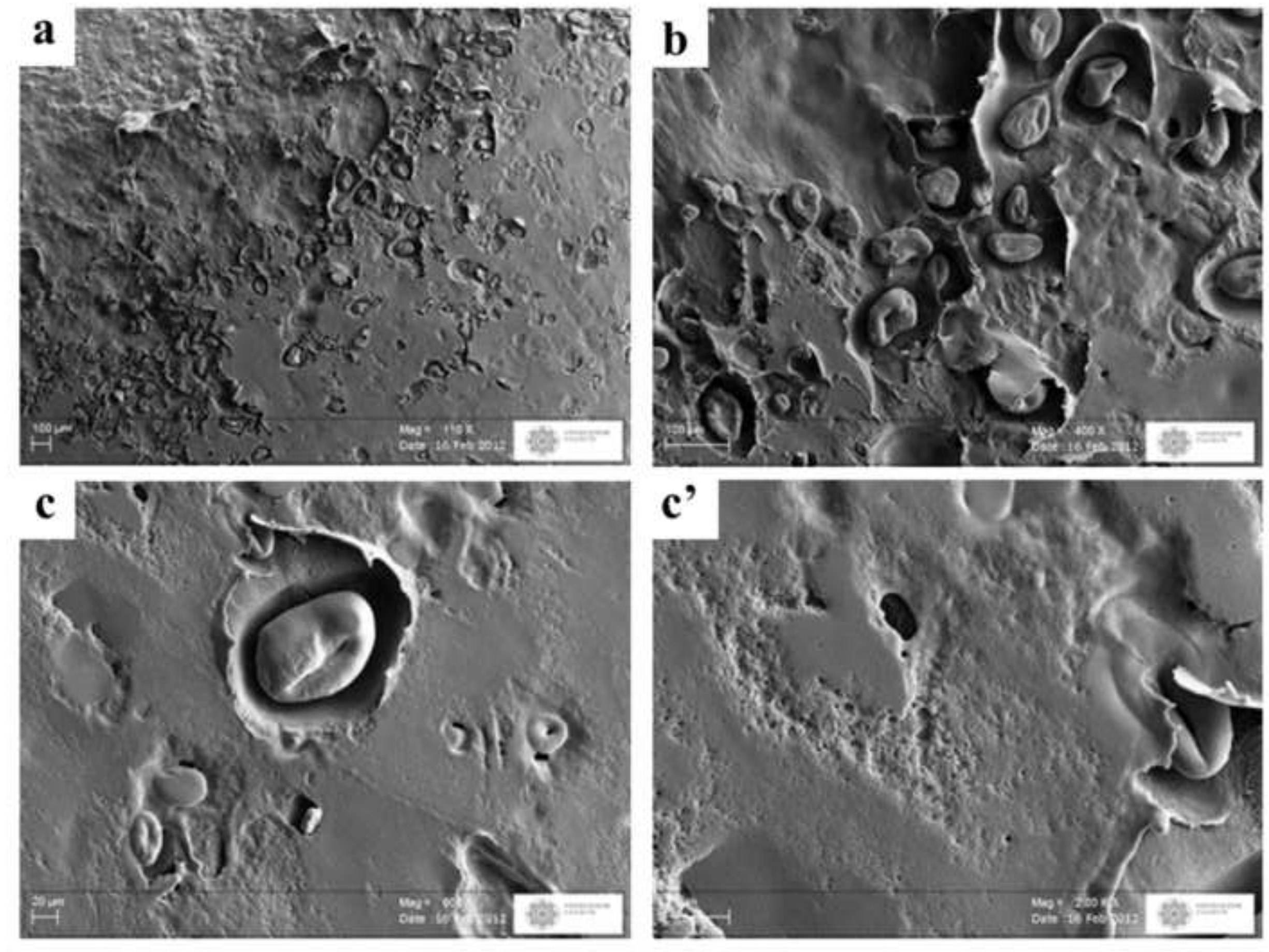
Figure 7
Click here to download high resolution image

\section{EXP2KIR}

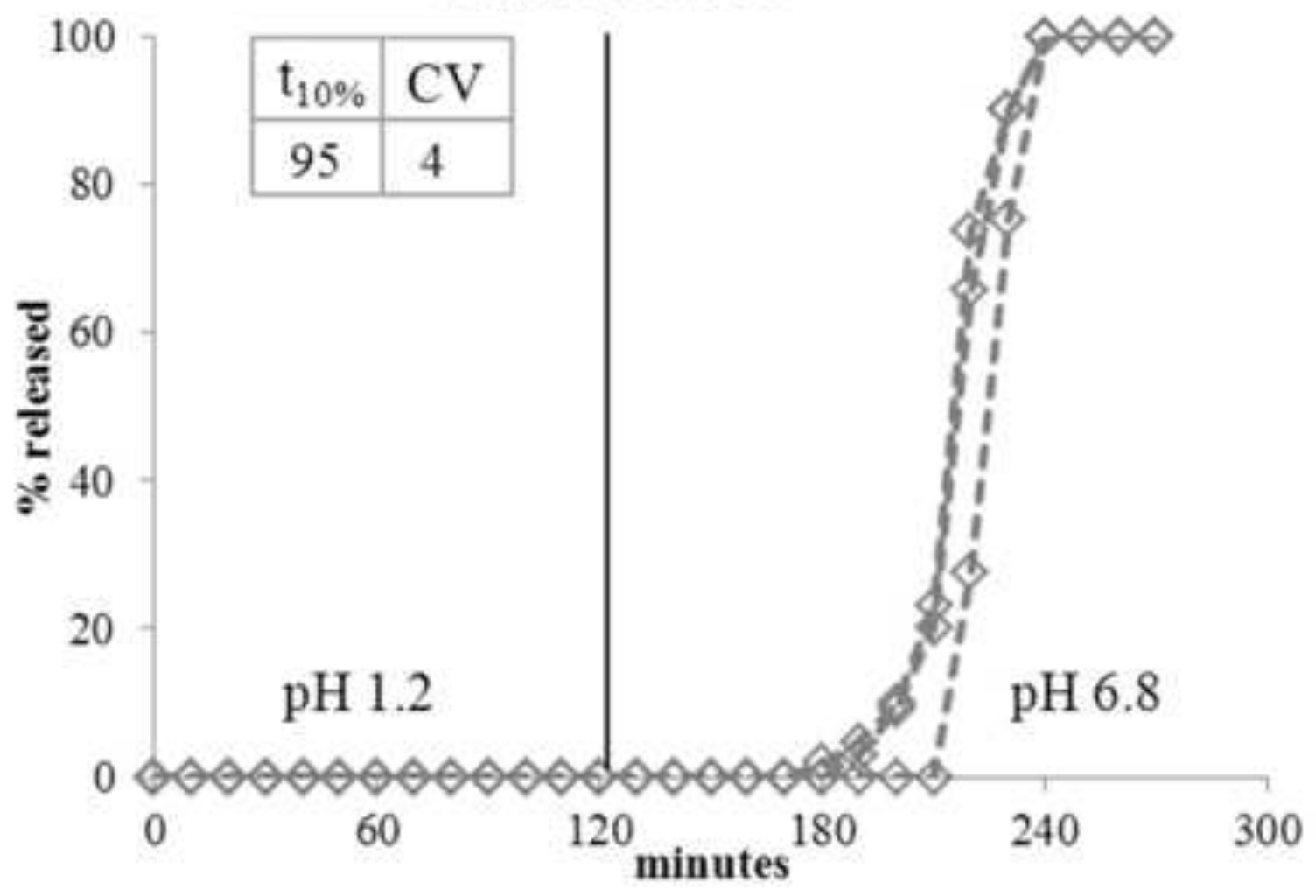

2EXP1KIR

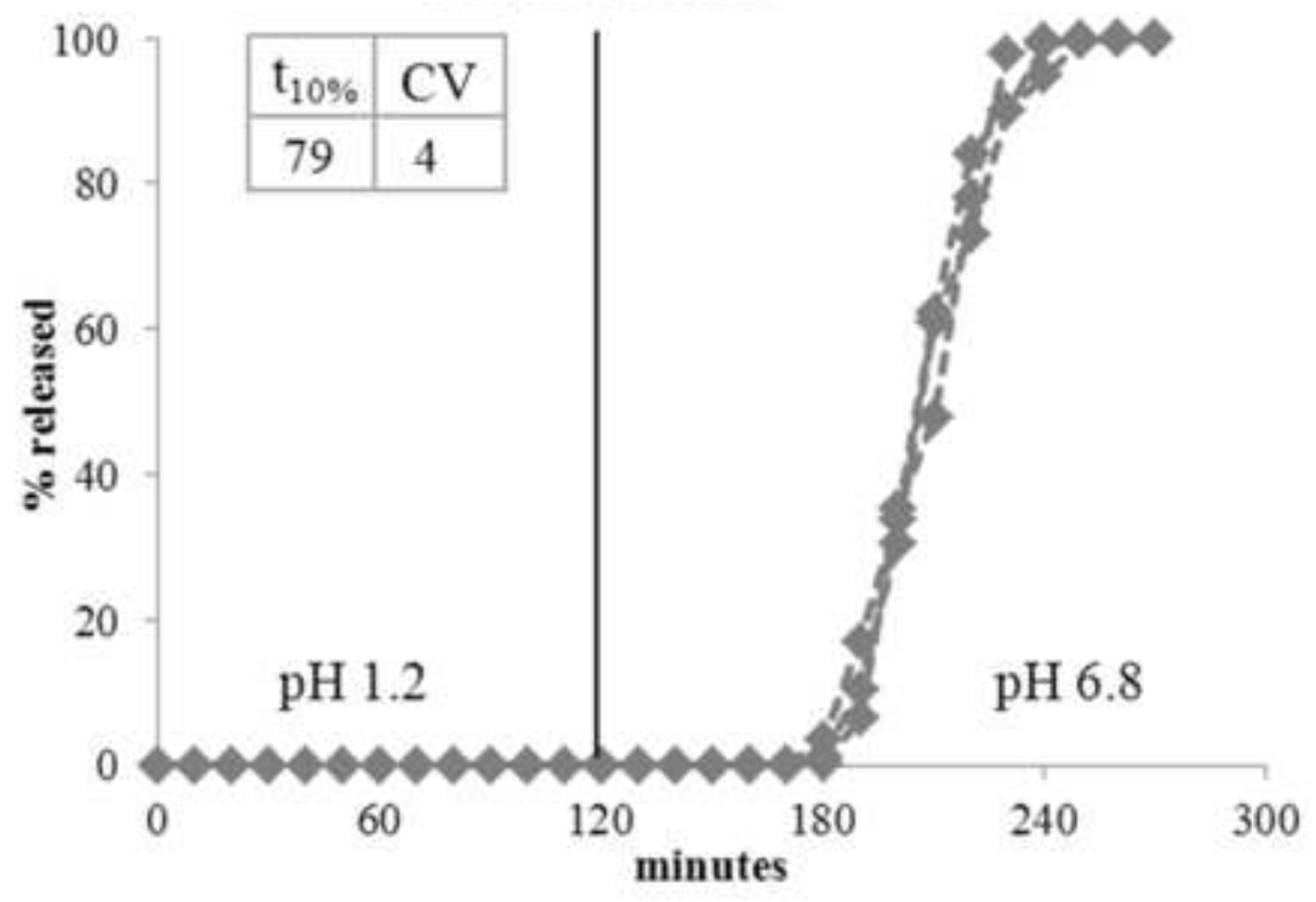




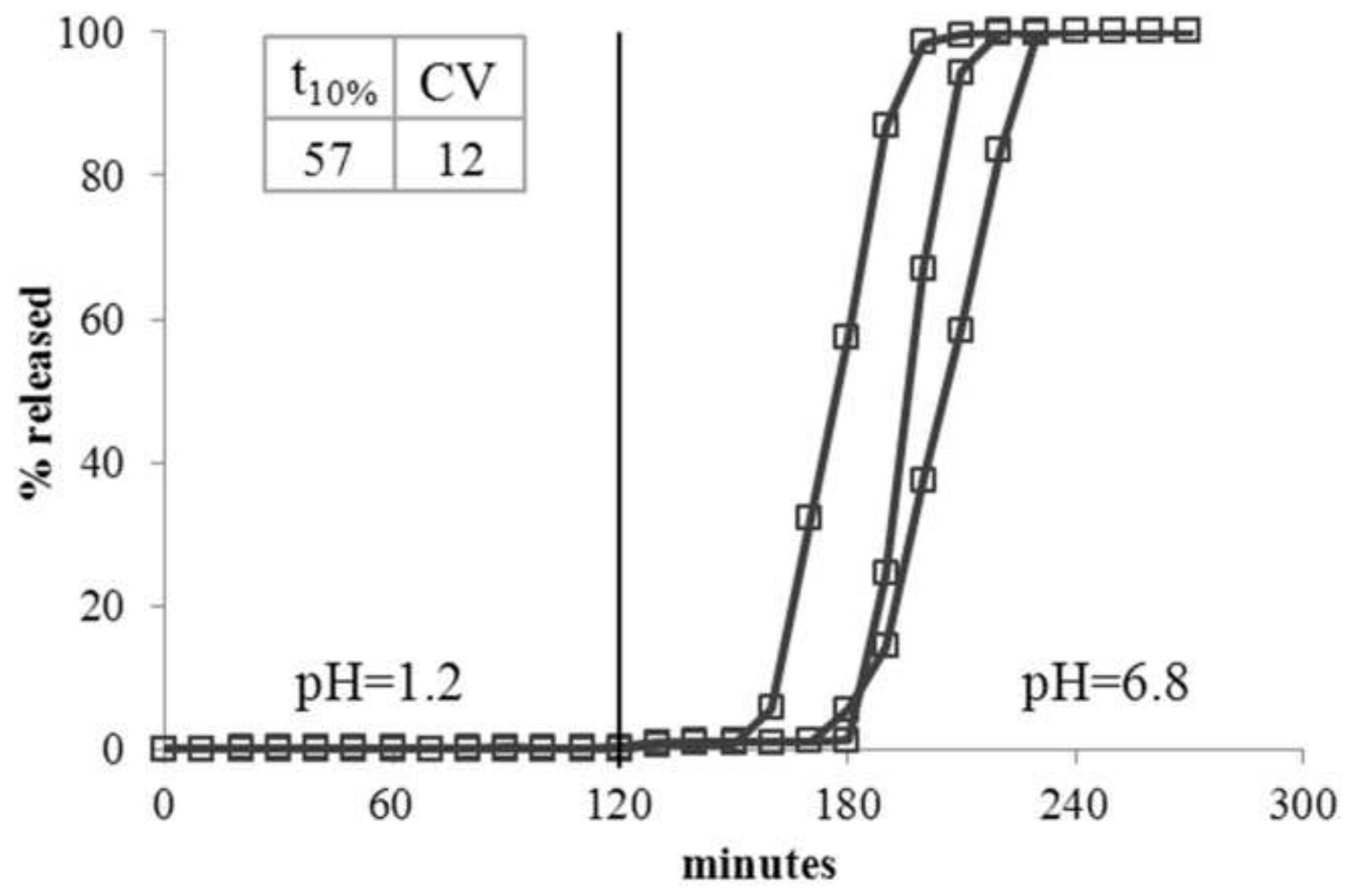

